\title{
Optimal Allocation of Photo-Voltaic Units in Radial Distribution Networks Using a New Student Psychology Based Optimization Algorithm
}

\author{
Subrat Kumar Dash ${ }^{1}$ and Sivkumar Mishra ${ }^{2}$ \\ ${ }^{1}$ Department of Electrical Engineering, \\ Govt. College of Engineering Kalahandi, Bhawanipatna, Odisha, India \\ ${ }^{2}$ Department of Electrical Engineering, \\ Centre for Advance Post Graduate Studies, Biju Patnaik University of Technology, \\ Odisha, Rourkela, India \\ dashsubratkumar@gmail.com,sivmishra@gmail.com
}

\begin{abstract}
This paper presents the first ever engineering application of a recently proposed metaheuristic algorithm namely, Student Psychology-based Optimization (SPBO) algorithm, which emulates the psychology of students in a class to continuously improve their class performance for becoming the best student. This algorithm is implemented for determining the optimal locations and sizes of Photo Voltaic (PV) units to minimize the real power loss of the system effectively by exploiting the requirement of minimal tuning parameters. The detailed steps of implementation include the proposed student classification based on normally distributed class performance. To prove the efficacy of the proposed approach three standard radial distribution networks i.e., 33-node, 69-node and 84-node networks are considered. The results obtained not only validate the successful implementation of the SPBO algorithm to the DG allocation problem but also proves its superiority over other recently proposed metaheuristic approaches in solving optimal allocation of PV units.
\end{abstract}

Keywords: Distributed generators; PV units; student psychology-based optimization; radial distribution network

Nomenclature

Mean of normal distribution $\mathrm{N}_{b}$

curve

$\sigma$

BS

Spread of normal distribution $\mathrm{V}_{\text {min }}$ curve

Good Student

AS Average Student

BAS Below average student

$p_{i j}^{k+1}$ performance of the $i^{\text {th }}$ student in
$\mathrm{j}^{\text {th }}$ subject for $(\mathrm{k}+1)^{\text {th }}$ iteration

$p_{\text {best }, i j}^{k}$

performance of the best student in $P_{D G}$ $\mathrm{j}^{\text {th }}$ subject for $\mathrm{k}^{\text {th }}$ iteration

$p_{r j}^{k}$ performance of any random
student of the class in $j^{\text {th }}$ subject for $\mathrm{k}^{\text {th }}$ iteration

$\alpha$ parameter which is randomly assigned a value of either 1 or 2

$p_{\text {average }}^{k}$ average performance of the student of class in $\mathrm{k}^{\text {th }}$ iteration $\mathrm{I}_{\mathrm{j}} \quad$ current flowing in $\mathrm{k}^{\text {th }}$ branch

$\mathrm{r}_{\mathrm{j}}$ Resistance of $\mathrm{k}^{\text {th }}$ branch
$\mathrm{V}_{\max }$

$I_{B, j}$

$I_{B, j}^{\max }$

$\mathrm{N}_{\mathrm{n}}$

$\mathrm{DG}_{\text {loc }}$

$n_{D G}$

iter_max

$\mathrm{N}_{\mathrm{S}}$

$\mathrm{V}_{\mathrm{L}}$

$\mathrm{V}_{\mathrm{U}}$
Total no of branches of DN

Minimum bus voltage

Maximum bus voltage

branch current flowing in $\mathrm{j}^{\text {th }}$ branch

maximum permissible branch current flow of $j^{\text {th }}$ branch

Total no of nodes of DN

Location of DG

Size of DG $(\mathrm{kW})$

No of DGs

Maximum no of iterations

No of students in a class

Lower limits of the design variable Upper limits of the design variable

Received: March $28^{\text {th }}, 2021$. Accepted: June $17^{\text {th }}, 2021$

DOI: $10.15676 /$ ijeei.2020.13.2.5 


\section{Introduction}

Distribution utilities (DU) are now facing the crunch of growing energy demand. This deficit of available energy and energy demand exacerbates the performance of the distribution network (DN). As reported in [1] almost $70 \%$ of power loss in the power system is incurred by the DN. One of the solutions to meet the current energy demand lies in reducing the losses in the DN. Therefore, DUs are constantly in search for the alternatives for power loss reduction. Several traditional measures that DUs look for are: (1) setting up new generating stations, (2) upgrading transmission and distribution infrastructures, (3), incorporating shunt capacitors (SC) and voltage regulators (VR) etc. But the first two options are very expensive as well as time consuming affairs. Though, shunt capacitors and voltage regulators offer local and inexpensive solution, the coordinated control of the two are quite intricate. Further, the dependence of reactive power output of the SC on the node voltage and ferro-resonance effects has resulted in the limited use of the shunt capacitors. In last two decades, renewable distributed generators (RDG) are getting widespread attention in providing clean energy at medium voltage level. Distributed generators (DG) are the small generator units such as photo voltaic (PV) modules, wind generators (WG), combined heat and power (CHP), gas turbines (GT) etc. which are directly connected to the consumer end without any transmission and distribution infrastructures [2]. DGs offers several opportunities to DN in terms of: (1) deferring construction of new central generation plants, (2) avoiding up gradation of transmission and distribution infrastructures, (3) improving voltage profile, (4) facilitating loss reduction, (5) enhancing stability margin, (6) providing clean energy, and (7) increasing reliability etc. Due to rapid technological advancement, PV modules with better efficiency are being manufactured at large scale at a much-reduced cost which make it a promising player in the current energy sector. Further, it is predicted that in between 2030 to 2050 , almost $10 \%$ to $30 \%$ of global energy demand will be served by solar PV alone [3].

Table 1. A review of various recently proposed DG allocation methods

\begin{tabular}{|c|c|c|}
\hline $\begin{array}{l}\text { Ref. } \\
\text { No. }\end{array}$ & $\begin{array}{l}\text { Authors } \\
\text { (Year) }\end{array}$ & Contribution \\
\hline 4 & $\begin{array}{l}\text { Truong et } \\
\text { al. }(2020)\end{array}$ & $\begin{array}{l}\text { Proposed a Quasi-Oppositional Chaotic Symbiotic Organisms } \\
\text { Search (QOCSOS) algorithm based optimal DG allocation method } \\
\text { for active power loss (APL), improving voltage profile (VP) and } \\
\text { enhancing voltage stability (VS). }\end{array}$ \\
\hline 8 & $\begin{array}{l}\text { Nugen and } \\
\text { Vo (2018) }\end{array}$ & $\begin{array}{l}\text { Implemented Stochastic Fractal Search (SFS) to solve OADG } \\
\text { problem for minimizing APL, improving VF and enhancing VS. }\end{array}$ \\
\hline 9 & $\begin{array}{l}\text { Gampa and } \\
\text { Das (2015) }\end{array}$ & $\begin{array}{l}\text { Proposed a new voltage sensitivity and apparent load power-based } \\
\text { sensitivity approach for placement of solar photovoltaic, wind and } \\
\text { biomass DGs. Genetic algorithm (GA) was used to find optimal size } \\
\text { of DGs considering both technical and economic factors for hourly } \\
\text { average load profile. }\end{array}$ \\
\hline 10 & $\begin{array}{l}\text { Barik and } \\
\text { Das (2018) }\end{array}$ & $\begin{array}{l}\text { Considered seasonal variation in load profile and DG output for } \\
\text { obtaining optimal DG sizes. }\end{array}$ \\
\hline 11 & $\begin{array}{l}\text { Raut et al. } \\
\text { (2019) }\end{array}$ & $\begin{array}{l}\text { Applied an adaptive Non-dominated Sorting Genetic Algorithm } \\
\text { (NSGA-II) for obtaining optimal allocation of DGs for minimizing } \\
\text { three objectives namely APL, DG operational cost (OC) and } \\
\text { emission cost (EC) }\end{array}$ \\
\hline 12 & $\begin{array}{l}\text { Nematshah } \\
\text { i and } \\
\text { Mashhadi } \\
(2019)\end{array}$ & $\begin{array}{l}\text { Proposed Distribution Locational Marginal Price (DLMP) using GA } \\
\text { to solve OADG. }\end{array}$ \\
\hline 13 & $\begin{array}{l}\text { Prassad et } \\
\text { al. }(2019)\end{array}$ & $\begin{array}{l}\text { Location for DG placement is determined using power loss index } \\
\text { (PLI) and Elephant Herding Optimization Algorithm (EHOA) is } \\
\text { used to determine the optimal size of unity power factor (UPF) DGs }\end{array}$ \\
\hline
\end{tabular}




\begin{tabular}{|c|c|c|}
\hline $\begin{array}{l}\text { Ref. } \\
\text { No. }\end{array}$ & $\begin{array}{l}\text { Authors } \\
\text { (Year) }\end{array}$ & Contribution \\
\hline & & and 0.9 power factor lagging DGs. \\
\hline 14 & $\begin{array}{l}\text { Kumar et } \\
\text { al. }(2019)\end{array}$ & $\begin{array}{l}\text { Formulated OADG problem in a pareto based multi-objective frame } \\
\text { work to maximize the economic and technical benefits. }\end{array}$ \\
\hline 15 & $\begin{array}{l}\text { Nagaballi } \\
\text { and Kale } \\
(2020)\end{array}$ & $\begin{array}{l}\text { Improved Raven Roosting Optimization (IRRO) algorithm was } \\
\text { implemented for optimal deployment of DGs for maximizing } \\
\text { techno-economic benefits. Further, game theory (GT) based pareto } \\
\text { optimal approach was proposed for obtaining the best solutions. }\end{array}$ \\
\hline 16 & $\begin{array}{l}\text { Suresh and } \\
\text { Edward } \\
(2020)\end{array}$ & $\begin{array}{l}\text { Applied a hybrid method of Grasshopper Optimization (GO) and } \\
\text { cuckoo search (CS) optimization to decide the optimal allocation of } \\
\text { DGs for minimizing line losses, DG Cost and improving VS. }\end{array}$ \\
\hline 17 & $\begin{array}{l}\text { Raut and } \\
\text { Mishra } \\
(2020)\end{array}$ & $\begin{array}{l}\text { OADG problem was solved using a Pareto-based multi-objective } \\
\text { Sine Cosine Algorithm (P-SCA) to minimize APL, enhance VS and } \\
\text { reduce DG OC }\end{array}$ \\
\hline 18 & $\begin{array}{l}\text { Khodabakh } \\
\text { shian and } \\
\text { Andishgar } \\
(2016)\end{array}$ & $\begin{array}{l}\text { Presented an Intersect Mutation Differential Evolution (IMDE) to } \\
\text { simultaneously determine the optimal location and size of DGs and } \\
\text { shunt capacitors (SC) in distribution networks for loss minimization. }\end{array}$ \\
\hline 19 & $\begin{array}{l}\text { Gampa and } \\
\text { Das (2019) }\end{array}$ & $\begin{array}{l}\text { Solved simultaneous DGs and SC allocation in radial distribution } \\
\text { system (RDS) using a combination of fuzzy and Genetic Algorithm } \\
\text { (GA)-based methodology to reduce active power and reactive power } \\
\text { supply, minimize APL, improvement of branch current capacity } \\
\text { (BCC), VP and VS. }\end{array}$ \\
\hline 20 & $\begin{array}{l}\text { Mahmoud } \\
\text { and } \\
\text { Lehtonen } \\
(2019)\end{array}$ & $\begin{array}{l}\text { Proposed a closed form analytical expression for simultaneous } \\
\text { allocation of multi type DGs and SC for reactive power loss (RPL) } \\
\text { minimization. }\end{array}$ \\
\hline 21 & $\begin{array}{l}\text { Gampa et } \\
\text { al (2020) }\end{array}$ & $\begin{array}{l}\text { A multi-objective frame work using Flower Pollination Algorithm } \\
\text { (FPA) based pareto optimal approach was proposed for optimal } \\
\text { network reconductoring of urban distribution systems integrated } \\
\text { with solar DGs and SC. }\end{array}$ \\
\hline 22 & $\begin{array}{l}\text { Almabsout } \\
\text { et } \quad \text { al. } \\
(2020)\end{array}$ & $\begin{array}{l}\text { Proposed a hybrid of local search and GA for determining optimal } \\
\text { placement and sizing of DGs and SC to minimize APL and total } \\
\text { voltage deviation (TVD). }\end{array}$ \\
\hline 23 & $\begin{array}{l}\text { Teimourza } \\
\text { deh and } \\
\text { Ivatloo } \\
(2020)\end{array}$ & $\begin{array}{l}\text { Formulized simultaneous DG allocation and network reconfiguration } \\
\text { (NR) using a three-dimensional Group Search Optimization } \\
\text { algorithm for loss minimization in RDS. }\end{array}$ \\
\hline 24 & $\begin{array}{l}\text { Raut and } \\
\text { Mishra } \\
(2020)\end{array}$ & $\begin{array}{l}\text { Presented simultaneous DG allocation and NR for minimization of } \\
\text { APL, enhancing VS, minimization of annual energy loss cost and } \\
\text { pollutant gas emission using improved multi-objective sine cosine } \\
\text { algorithm. }\end{array}$ \\
\hline 25 & $\begin{array}{l}\text { Tolabi et } \\
\text { al. }(2020)\end{array}$ & $\begin{array}{l}\text { Applied a new Thief and Police Algorithm (TPA) to determine } \\
\text { optimal location and sizes of SC, photovoltaic (PV) unit, wind } \\
\text { turbine (WT) unit and network reconfiguration to minimize APL, } \\
\text { OC and improvement in VS of the RDS. }\end{array}$ \\
\hline 26 & $\begin{array}{l}\text { Tran et al. } \\
(2020)\end{array}$ & $\begin{array}{l}\text { Implemented Stochastic Fractal Search Algorithm (SFSA) for } \\
\text { optimal allocation of DG units along with NR. }\end{array}$ \\
\hline 27 & $\begin{array}{l}\text { Ghatak et } \\
\text { al. (2017) }\end{array}$ & $\begin{array}{l}\text { Proposed an improved particle swarm optimization (PSO) technique, } \\
\text { with adaptive inertia weight based on success rate to optimally } \\
\text { allocate DGs and distributed static compensators (DSTATCOM) }\end{array}$ \\
\hline
\end{tabular}




\begin{tabular}{|c|c|c|}
\hline $\begin{array}{l}\text { Ref. } \\
\text { No. }\end{array}$ & $\begin{array}{l}\text { Authors } \\
\text { (Year) }\end{array}$ & Contribution \\
\hline & & considering technical, economic and social objectives. \\
\hline 28 & $\begin{array}{l}\text { Iqbal et al. } \\
(2018)\end{array}$ & $\begin{array}{l}\text { Presented an approach for simultaneous DG and DSTATCOM } \\
\text { allocation for minimization of APL and improvement in VP. }\end{array}$ \\
\hline 29 & $\begin{array}{l}\text { Ganesh } \\
\text { and } \\
\text { Kanimozhi } \\
(2018)\end{array}$ & $\begin{array}{l}\text { Suggested simultaneous allocations of PV arrays, DSTATCOM and } \\
\text { NR using multi-objective modified FPA for APL minimization, VF } \\
\text { enhancement and load balancing (LB). }\end{array}$ \\
\hline 30 & $\begin{array}{l}\text { Gampa et } \\
\text { al. }(2020)\end{array}$ & $\begin{array}{l}\text { Proposed a two-stage Grasshopper Optimization Algorithm (GOA) } \\
\text { based fuzzy multi-objective approach for allocation of DGs, SCs and } \\
\text { electric vehicle (EV) charging stations for distribution systems. At } \\
\text { first simultaneous DGs and SCs allocation was carried to using } \\
\text { fuzzy GOA approach to improve the substation power factor, APL } \\
\text { reduction and improvement of VF. Later, fuzzy GOA approach was } \\
\text { used for determining optimal locations for EV charging stations and } \\
\text { number of vehicles at the charging stations in presence of optimally } \\
\text { allocated DGs and SCs. }\end{array}$ \\
\hline 31 & $\begin{array}{l}\text { Mukhopad } \\
\text { hyay and } \\
\text { Das (2020) }\end{array}$ & $\begin{array}{l}\text { PSO based approach was suggested to determine optimal location } \\
\text { and sizing of PV DG and battery energy storage system (BESS) } \\
\text { along with NR to achieve minimum APL, improvement in VF and } \\
\text { loadability. }\end{array}$ \\
\hline 32 & $\begin{array}{l}\text { Pal et al. } \\
(2020)\end{array}$ & $\begin{array}{l}\text { OADG is solved using different meta-heuristic approaches like salp } \\
\text { swarm optimization (SSP), whale optimization algorithm (WOA), } \\
\text { moth flame optimization (MFO), modified one by one search } \\
\text { algorithm (MOBOSA) and grey wolf optimization algorithm } \\
\text { (GWOA) to minimize APL and energy loss (EL). }\end{array}$ \\
\hline 33 & $\begin{array}{l}\text { Babu et al. } \\
(2020)\end{array}$ & $\begin{array}{l}\text { Applied Harris Hawk Optimization (HHO) and Teaching Learning- } \\
\text { Based Optimization (TLBO) to allocate different types of DGs. }\end{array}$ \\
\hline 34 & $\begin{array}{l}\text { Khetrapal } \\
\text { et al. } \\
(2020)\end{array}$ & $\begin{array}{l}\text { Improved artificial bee colony (IABC) is applied to solve OADG for } \\
\text { APL minimization considering different types DG units. }\end{array}$ \\
\hline 35 & $\begin{array}{l}\text { Raut and } \\
\text { Mishra } \\
(2021)\end{array}$ & $\begin{array}{l}\text { Proposed an enhanced Sine Cosine algorithm for simultaneous DG } \\
\text { allocation and network reconfiguration to optimize active power loss } \\
\text { index, voltage stability index and voltage profile improvement } \\
\text { index, total system operation cost index and expected energy not } \\
\text { supplied index. }\end{array}$ \\
\hline
\end{tabular}

DNs traditionally operate in radial topology and are designed to be passive. However, inclusions of DGs affect the voltage profile and branch flows of DN as well as force it to be active. Therefore, the improper allocations of DG can adversely affect the DN performance by increasing the power loss and rise in voltage level [4]. Hence, to derive maximum benefits, DGs of optimal size must be inserted at appropriate node of the DN. This has inducted a lot of research in past decade as evident from the literature. Different methods have been suggested to find the optimal allocation of DGs (OADG) which can be grouped under analytical methods and metaheuristic methods. Though analytical methods are easy to implement and can give a quick solution, their uses are restricted because of inability to handle different DG parameters (such as type of DGs, power factor of DGs), multiple objective functions and difficulty in handling large DNs. But recently, meta-heuristic-based approaches are becoming popular in solving OADG problem as they can give near optimal solutions and can handle pragmatic multi-objective functions at ease. Over the past decades, OADG problem has been transformed from mere mono objective to multi objectives, dispatchable DGs to non-dispatchable DGs, deterministic loads to dynamic time varying loads, exclusive DGs allocation to allocation of 
DGs with several other compensating devices (shunt capacitors, D-FACTS devices, energy storage system, network reconfiguration). A survey of some recently published papers concerned to DG allocation problem is presented in Table-1

Summaries of reviews presented above suggests, that different metaheuristic approaches such as QOCSOS [4], SFS [8], GA [9,12], NSGA-II [11], EOHA [13], IRRO [15], hybrid of GO and CS [16], P-SCA [17], IMDE [18], FPA [21], TPA [25], SFSA [26], WOA [32], SSP [32], MFO [32], MOBOSA [32], GWOA [32], HHO [33], IABC [34] are being applied to solve OADG aiming to get better quality of solution. Power loss minimization being the most common objective adopted by most of the earlier authors $[4,8,11,13,17,18,19,20,22,23$, $24,25,26,28,29,31,34,35]$, as it directly impacts the economic savings of the DUs. Few, authors [27-29] have also solved OADG along with DSTATCOM without investigating the impact on coordinated control of these devices. As per the prevailing grid code standard [36], DGs operating at unity power factor only considered for integration at medium voltage level. Solar PVs are the fastest growing unity power factor DGs that are economically competitive with central power generators.

In light of the above discussions, the major contribution of the paper is to (1) propose the first ever engineering implementation of a new metaheuristic algorithm namely student psychology based optimization (SPBO) to solve optimal allocation of multiple PV DGs for loss minimization, (2) incorporate a strategy for classification of students based on normal distribution for implementation of the SPBO to solve OADG problem and (3) validate the proposed approach on three commonly used test systems i.e. 33-node 69-node, and 84-node DN.

This article is organized as follows: the newly proposed SPBO algorithm is presented with some modified approaches in section 2. In section 3 and 4, the OADG problem is formulated for the optimization with SPBO algorithm. Section 5 presents the results for the 33, 69 and 84 node test distribution systems with a critical comparison of the results with that reported in recent literature. Section 6 concludes with the clear findings of the paper.

\section{Student Psychology Based Optimization Algorithm}

SPBO is a recently proposed meta-heuristic algorithm that emulates the psychology of students to improve their performance in all the subjects offered, in order to secure the best position in the class [5]. Class performance of a student is often guided by several factors like student's interest, efficiency and capability etc., which makes it a random process. In order to imitate this, a normal distribution characterized by mean or average value $(\mu)$ and the spread $(\sigma)$ which explicitly matches the random process of the students' performance in a class is proposed in this paper as shown in Figure 1. As the psychology of an individual student to perform in the examination is different from others, it is also proposed to club students of different groups who will have similar psychology. Therefore, based on the normal distribution, students of a class are grouped into four categories namely: Best Student (BS), Good Students (GS), Average Students (AS) and Below Average Students (BAS) heuristically as shown in Figure 1.

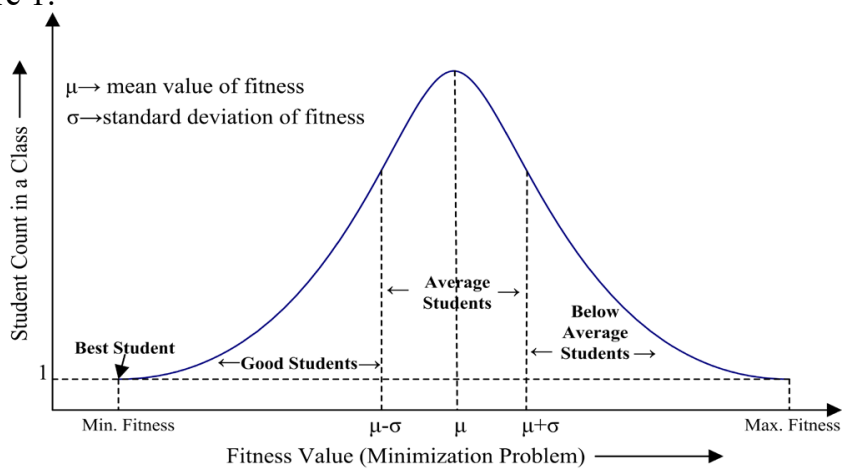

Figure 1. Proposed categorization of students using normal distribution. 
In contrast to the original SPBO algorithm, here overall student's performance is considered to categorize a student into any of the aforementioned group. First of all, it helps in alleviating ambiguity pertaining to the classification of students, which was not explicitly mentioned in the paper [5]. Secondly, it allows implementation of the SPBO algorithm to real life engineering problem such as OADG as presented here. It also relieves computational burden by classifying students into different groups based on their overall performance considering all subject rather than considering performance in each individual subject.

The psychology of students to improve their performance is often different for students belonging to different groups. A student who secures highest mark / grade in the examination is regarded as the best student. For a best student it may be essential to perform better in the examination than any other student. So, his/her improvement in performance may be expressed as in (1)

$$
p_{i j}^{k+1}=p_{\text {best }, i j}^{k}+(-1)^{\alpha} \times \text { rand } \times\left(p_{\text {best }, i j}^{k}-p_{r j}^{k}\right)
$$

Where, $p_{i j}^{k+1}$ is the performance of the $\mathrm{i}^{\text {th }}$ student in $\mathrm{j}^{\text {th }}$ subject for $(\mathrm{k}+1)^{\text {th }}$ iteration, $p_{b e s t, i j}^{k}$ is the performance of the best student in $\mathrm{j}^{\text {th }}$ subject for $\mathrm{k}^{\text {th }}$ iteration, $p_{r j}^{k}$ is the performance of any random student of the class in $\mathrm{j}^{\text {th }}$ subject for $\mathrm{k}^{\text {th }}$ iteration and $\alpha$ is a parameter which is randomly assigned a value of either 1 or 2 . Students belongs to GS category often try to put more effort than the best student of the class so as to be the best student. Their efforts are represented by (2). However, some of the GS may try to put better effort than AS and at the same time tries to follow the BS which is clearly expressed in (3)

$$
\begin{aligned}
& p_{i j}^{k+1}=p_{\text {best }, i j}^{k}+\operatorname{rand} \times\left(p_{\text {best }, i j}^{k}-p_{i j}^{k}\right) \\
& p_{i j}^{k+1}=p_{i j}^{k}+\left\lfloor\text { rand } \times\left(p_{\text {best }, i j}^{k}-p_{i j}^{k}\right)\right]+\left[\text { rand } \times\left(p_{i j}^{k}-p_{\text {average }}^{k}\right)\right]
\end{aligned}
$$

Where, $p_{\text {average }}^{k}$ is the average performance of the student of class in $\mathrm{k}^{\text {th }}$ iteration.

In case of average students (AS), where students try to put average efforts, the performance may be represented as in (4).

$$
p_{i j}^{k+1}=p_{i j}^{k}+\left\lfloor\text { rand } \times\left(p_{\text {average }}^{k}-p_{i j}^{k}\right)\right\rfloor
$$

A BAS does not have any structured approach towards improving his/her performance rather it can be best described as a random approach as represented in (5).

$$
p_{i j}^{k+1}=p_{\min , j}+\left[\text { rand } \times\left(p_{\max , j}-p_{\min , j}\right)\right]
$$

SPBO algorithm does not have any explicit control parameters except the two trivial parameters like: size of the population (class size), and maximum number of iterations. Further, it has performed better as compared to other state-of-the-art metaheuristic approaches in solving standard benchmark functions as claimed in [5]. Therefore, it makes it a strong contender against the recent state-of-the-art metaheuristic approaches to be applied for solving different optimization problems.

\section{Problem Formulation}

Here, SPBO algorithm is used to find the optimal location as well as size of DGs (PV units) for minimizing active power loss of the network while satisfying the system constraints as formulated below.

\section{A. Objective Function}

From DU point of view real power loss reduction is the prime objective for insertion of DGs, as over a time period this power loss reduction will be reflected as energy savings. The power loss of the DN can be expressed as 


$$
P_{\text {loss }}=\sum_{j=1}^{N_{b}}\left|I_{j}\right|^{2} r_{j}
$$

Where, $I_{j}$ is the current flowing in $j^{\text {th }}$ branch and $r_{j}$ is the corresponding branch resistance. $N_{b}$ represents the total no of branches of the network.

So, the objective function can now be formulated as in (7)

$$
f=\min \left(P_{\text {loss }}\right)
$$

\section{B. Constraints}

The objective function defined in (7) is optimized using SPBO for the following pragmatic constraints.

- Bus Voltage Constraint:

The bus voltage is allowed to vary within $-5 \%$ to $+5 \%$ of the nominal voltage.

$V_{\min } \leq V_{i} \leq V_{\max }$

- Branch Flow Constraint:

DGs can affect the branch flow of the network. So, to restrict the branch flow in presence

DGs within the safe limits following constraint is defined.

$$
I_{B, j} \leq I_{B, j}^{\max }
$$

Where, $I_{B, j}$ is the branch current flowing in $\mathrm{j}^{\text {th }}$ branch and $I_{B, j}^{\max }$ is the maximum permissible branch current flow of $j^{\text {th }}$ branch.

- DG Position Constraint:

The nodes for DG integration are generated using (10) without any repetition

$$
2 \leq D G_{l o c} \leq N n
$$

- DG Capacity Constraints:

The sizes of DGs must be within its capacity limit as defined in (11)

$$
0.1 \times \sum P_{l, i}<P_{D G}<0.6 \times \sum P_{l, i}
$$

\section{Implementation of SPBO Algorithm to OADG \\ A. Generation of initial population}

In this work SPBO algorithm is used to determine the optimal location and size of the DGs to be placed in the DN for minimizing the real power loss. In SPBO algorithm each feasible solution vector $\left(\mathrm{P}_{\mathrm{i}}\right)$ is termed as performance of the students while each entry $\left(\mathrm{p}_{\mathrm{ij}}\right)$ represents performance in different subjects. The solution vectors contain location and size of DGs for a specified number of DGs (nDG) as expressed in (12).

$$
P_{i}=\left\lfloor l o c_{i, 1} l o c_{i, 2}, \ldots, l o c_{i, n D G}, P_{D G i, 1}, P_{D G i, 1, \ldots P_{D G i, n D G}}\right\rfloor
$$

These solutions are randomly initialized which are uniformly spread across the entire solution space as expressed in (13) \& (14).

$$
\begin{aligned}
& l o c_{i}=\operatorname{round}\left(l o c_{i, \text { min }}+\operatorname{rand}\left(\operatorname{loc}_{i, \text { max }}-l o c_{i, \text { min }}\right)\right) \\
& P_{D G, i}=P_{D G i, \min }+\operatorname{rand}\left(P_{D G i, \max }-P_{D G i, \min }\right)
\end{aligned}
$$

\section{B. Detail steps of Implementation}

The detailed steps for implementing SPBO algorithm to OADG problem is outlined below. Step 1: Input the system data i.e., line data and load data Step 2: Set $\mathrm{nDG}$, maximum iteration (iter_max), no of student $\left(\mathrm{N}_{\mathrm{S}}\right)$, lower $\left(\mathrm{V}_{\mathrm{L}}\right)$ and upper limits $\left(\mathrm{V}_{\mathrm{U}}\right)$ of the design variable. 
Step 3: Randomly generate the initial class performance as $P=\left[p_{1}, p_{2}, \ldots, p_{N S}\right]^{T}$ where each $\mathrm{P}$ contains the location and size of DG.

Step 4: Evaluate the initial class performance using (7). This is done by performing load flow [6]

Step 5: Set the iteration counter $\mathrm{k}=1$.

Step 6: Classify students into different group such as BS, GS, AS, BAS

Step 7: Update the class performance of each student belonging to different groups using (1-5) as applicable.

Step 8: Evaluate the performance of the class for updated class using (7)

Step 9: If the present class performance is better than the previous class performance then replace the previous class with present class.

Step 10: If maximum iteration is reached then go to step 11 else increment the iteration counter $\mathrm{k}=\mathrm{k}+1$ and go to step 6 .

Step 11: Print the best solution

\section{Result and Discussion}

To validate the proposed approach, three standard test system i.e., 33-node 69-node, and 84-node radial DN were considered. SPBO algorithm is implemented with necessary modification to obtain the optimal location and size of the DGs for real power loss minimization. A forward backward based load flow [6] is used to evaluate the objective function. Best results are recorded for 10 independent runs of the algorithm on the three test systems. Interestingly, except initial population size and maximum number of iterations, the algorithm does not have any implicit parameters to be tuned. For each case, a class size of 40 and maximum iterations of 150 were set. In this study, photovoltaic DGs capable of injecting real power only have been considered. The sizes of DGs are varied as expressed in (11) and total three no of DGs were considered for integration. The proposed algorithm is programmed in MATLAB R2016a environment on a pc with Intel(R) Core (TM) i3-6006U CPU @2.00 GHz, 4GB RAM.

\section{A. 33-node $D N$}

The proposed approach is first tested on a 33-node radial distribution network [7] which has a total real and reactive power demand of $3715 \mathrm{~kW}$ and $2300 \mathrm{kVAr}$ respectively. The said test system has a real and reactive power loss of $210.98 \mathrm{~kW}$ and $143.02 \mathrm{kVAr}$ respectively prior to the integration of DGs into the network. The system experiences a minimum voltage of 0.9038 p.u. at $18^{\text {th }}$ node.

In Table 2, the optimal allocations (locations and sizes) of DGs for minimizing real power loss of the system using proposed approach is presented. Table 2 also compares the best results obtained by recently reported different optimization techniques to determine the locations and sizes of DGs to optimize the real power loss. Using SPBO algorithm the real power loss of the system has been reduced from $210.98 \mathrm{~kW}$ to $72.1382 \mathrm{~kW}$ which is the lowest among the reported approaches. Locations for DG integration obtained by the proposed method are different than other reported methods except for the node no. 24. Figure 2 shows the convergence characteristic of the proposed SPBO algorithm in optimizing the real power loss of the DN. Voltage profile and branch current profile of the DN with and without integration of 
DGs are depicted in Figure 3 and Figure 4 respectively. It is clear that in presence of the DGs the system operates at a much better voltage profile than without DGs and the application of SPBO results in better voltage and current profiles compared to the other three methods $[2,4,8]$. A reversal of branch flow can be noticed in branches adjacent to the DGs interconnected nodes. However, the magnitude of these reverse currents is the lowest in the proposed method as compared to the other reported methods as seen in Figure 4.

Table 2. Comparison of results for 33-node DN

\begin{tabular}{|l|c|c|c|}
\hline \multirow{2}{*}{ Methods } & $\begin{array}{c}\text { DG } \\
\text { Location }\end{array}$ & $\begin{array}{c}\text { DG Size } \\
(\mathrm{MW})\end{array}$ & \multirow{2}{*}{$\begin{array}{c}\text { Ploss } \\
(\mathrm{kW})\end{array}$} \\
\hline \multirow{3}{*}{ MRFO [1] } & 24 & 1.0171 & \multirow{2}{*}{72.876} \\
\cline { 2 - 3 } & 13 & 0.7882 & \\
\cline { 2 - 3 } & 30 & 1.0353 & \\
\hline \multirow{3}{*}{ QOCSOS [4] } & 13 & 0.8017 & \multirow{3}{*}{72.7869} \\
\cline { 2 - 3 } & 24 & 1.0913 & \\
\cline { 2 - 3 } & 30 & 1.0537 & \\
\cline { 2 - 3 } SFSA [8] & 13 & 0.8020 & \multirow{3}{*}{72.785} \\
\cline { 2 - 3 } & 24 & 1.0920 & \\
\hline \multirow{2}{*}{$\begin{array}{l}\text { SPBO } \\
\text { (Proposed) }\end{array}$} & 30 & 1.0537 & \\
\cline { 2 - 3 } & 24 & 1.2375 & \multirow{2}{*}{1.3152} \\
\cline { 2 - 3 } & 14 & 0.8230 & \\
\hline
\end{tabular}

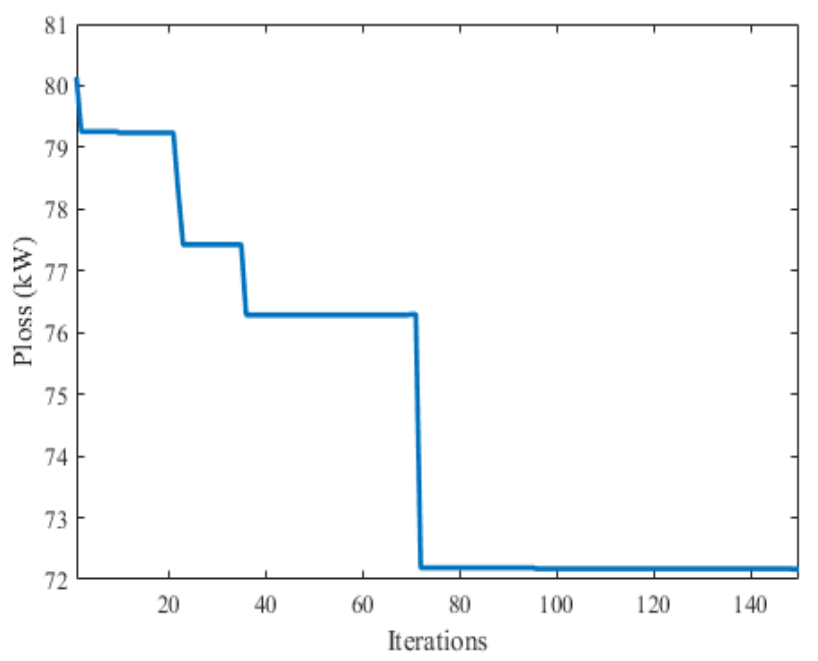

Figure 2. Convergence characteristic of SPBO algorithm for 33-node DN 


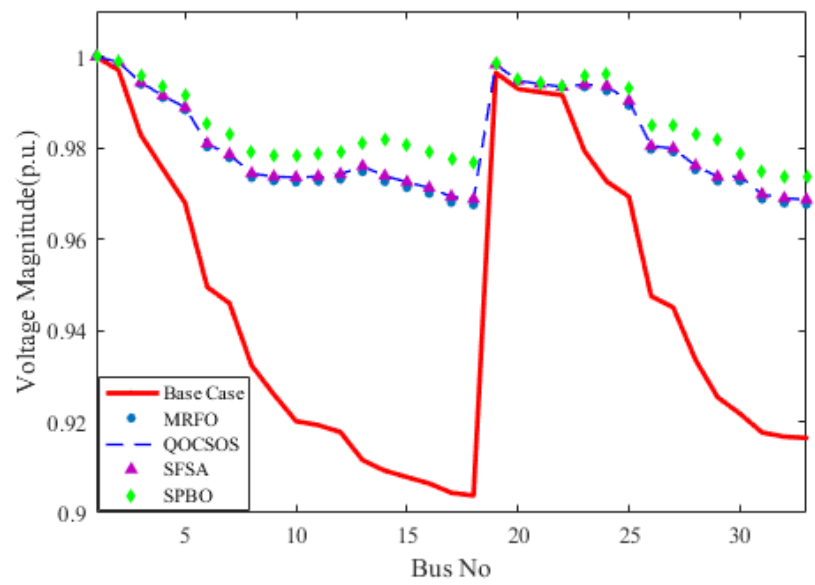

Figure 3. Voltage profile of 33-node DN with and without DGs

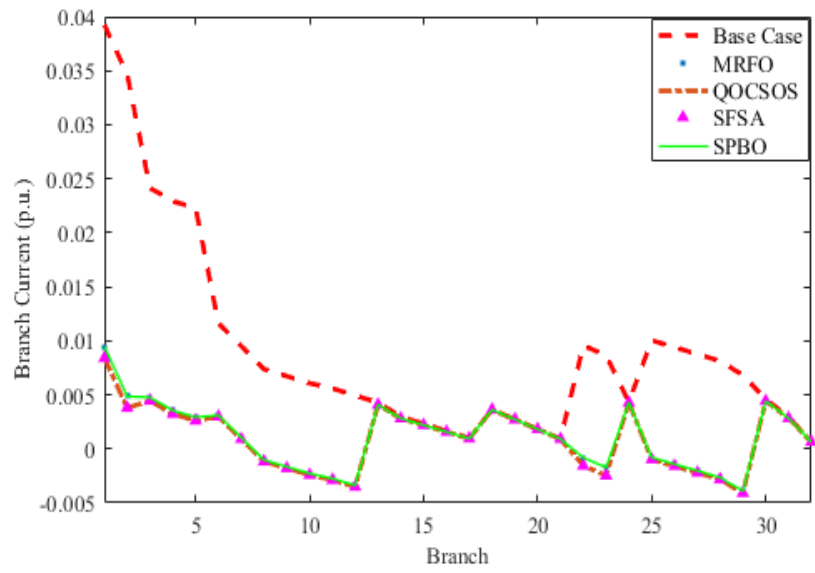

Figure 4. Branch current of 33-node DN with and without DGs

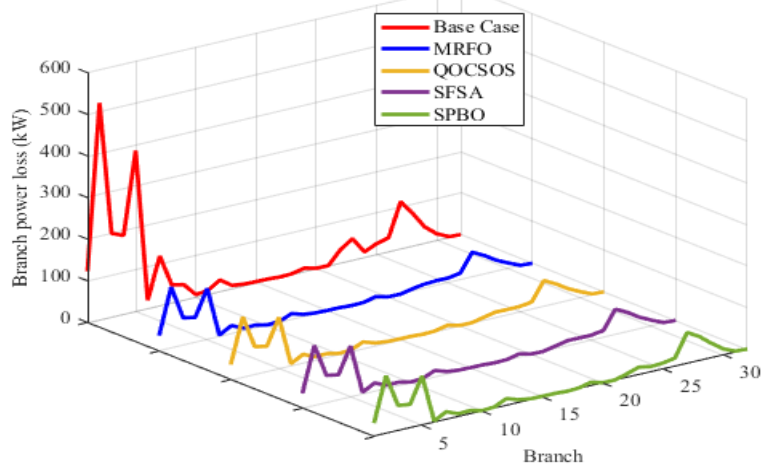

Figure 5. Branch power loss of 33-node DN with and without DGs 
In Figure 5, a comparison of branch loss profiles for the base case along with for all compared methods have been presented for the 33-bus system. It is worth noting that in presence of optimally allocated DGs the branch-wise power loss is significantly reduced than the base case system.

\section{B. 69-node DN}

The proposed approach is then tested on a 69-node radial distribution network [7] which has a total real and reactive power demand of $3791.9 \mathrm{~kW}$ and $2694.1 \mathrm{kVAr}$ respectively. The said test system has a real and reactive power loss of $224.92 \mathrm{~kW}$ and $102.13 \mathrm{kVAr}$ respectively prior to the integration of DGs into the network. The system experiences a minimum voltage of 0.9092 p.u. at $65^{\text {th }}$ node.

In Table 3, the optimal allocations (locations and sizes) of DGs for minimizing real power loss of the system using proposed approach is presented. Table 3 also compares the best results obtained by recently reported different optimization techniques to determine the locations and sizes of DGs to optimize the real power loss. Using SPBO algorithm the real power loss of the system has been reduced from $224.92 \mathrm{~kW}$ to $68.6447 \mathrm{~kW}$ which is the lowest among the reported approaches. Locations for DG integration obtained by the proposed method are different than other reported methods except for the first node. Figure 6 shows the convergence characteristic of the proposed SPBO algorithm in optimizing the real power loss of the DN. Voltage profile and branch current of the DN with and without integration of DGs are depicted in Figure 7 and Figure 8 respectively. It is clear that in presence of the DGs the system operates at a much better voltage profile than without DGs. The voltage profile obtained by the proposed SPBO algorithm is almost similar to the other six algorithms as reported in literature. A reversal of branch flow can be noticed in branches adjacent to the DGs interconnected nodes. However, the magnitude of this reverse current is negligible as can been from Figure 8. Further, the current drawn from the substation is minimum for results obtained by SPBO than rest of the methods as apparent from Figure 8.

Table 3. Comparison of results for 69-node DN

\begin{tabular}{|c|c|c|c|}
\hline Methods & $\begin{array}{c}\text { DG } \\
\text { Location }\end{array}$ & $\begin{array}{l}\text { DG Size } \\
\text { (MW) }\end{array}$ & $\begin{array}{l}\text { Ploss } \\
(\mathrm{kW})\end{array}$ \\
\hline \multirow{3}{*}{ MRFO [1] } & 61 & 1.7134 & \multirow{3}{*}{69.4256} \\
\hline & 18 & 0.3691 & \\
\hline & 11 & 0.5242 & \\
\hline \multirow{3}{*}{ QOCSOS [4] } & 11 & 0.5269 & \multirow{3}{*}{69.4284} \\
\hline & 18 & 0.3803 & \\
\hline & 61 & 1.7190 & \\
\hline \multirow{3}{*}{ SFSA [8] } & 11 & 0.5273 & \multirow{3}{*}{69.428} \\
\hline & 18 & 0.3805 & \\
\hline & 61 & 1.7198 & \\
\hline \multirow{3}{*}{ GWO [32] } & 11 & 0.5415 & \multirow{3}{*}{69.51} \\
\hline & 18 & 0.4063 & \\
\hline & 61 & 1.7514 & \\
\hline \multirow{3}{*}{ MFO [32] } & 11 & 0.527 & \multirow{3}{*}{69.419} \\
\hline & 61 & 1.719 & \\
\hline & 18 & 0.380 & \\
\hline \multirow{3}{*}{ HHO [33] } & 11 & 0.5421 & \multirow{3}{*}{69.431} \\
\hline & 17 & 0.3726 & \\
\hline & 61 & 1.7158 & \\
\hline \multirow{3}{*}{$\begin{array}{l}\text { SPBO } \\
\text { (Proposed) }\end{array}$} & 49 & 0.7039 & \multirow{3}{*}{68.6447} \\
\hline & 15 & 0.6088 & \\
\hline & 61 & 1.7932 & \\
\hline
\end{tabular}




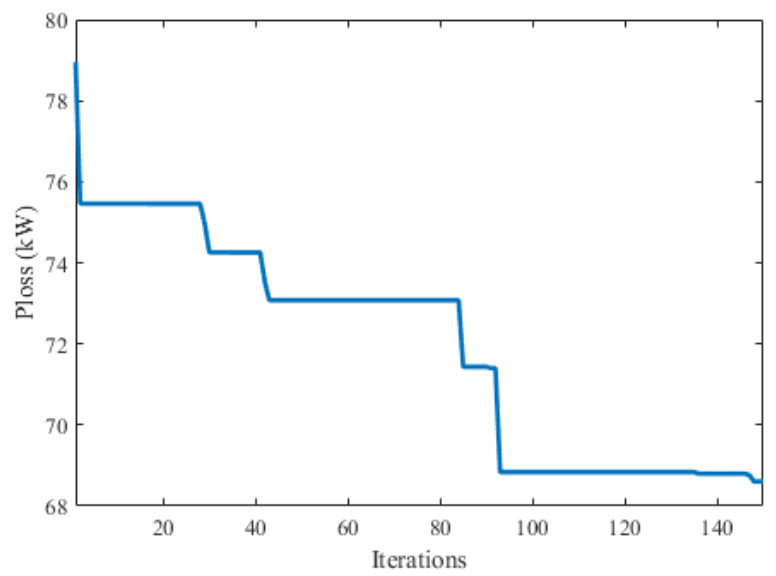

Figure 6. Convergence characteristic of SPBO algorithm for 69-node DN.

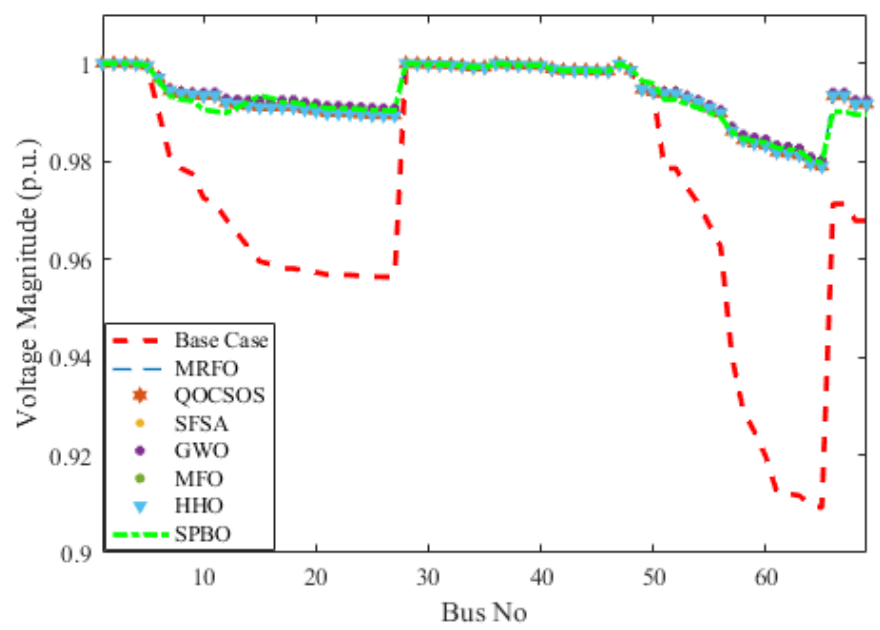

Figure 7 . Voltage protile of 69 -node $\mathrm{DN}$ with and without $\mathrm{DG}$ is

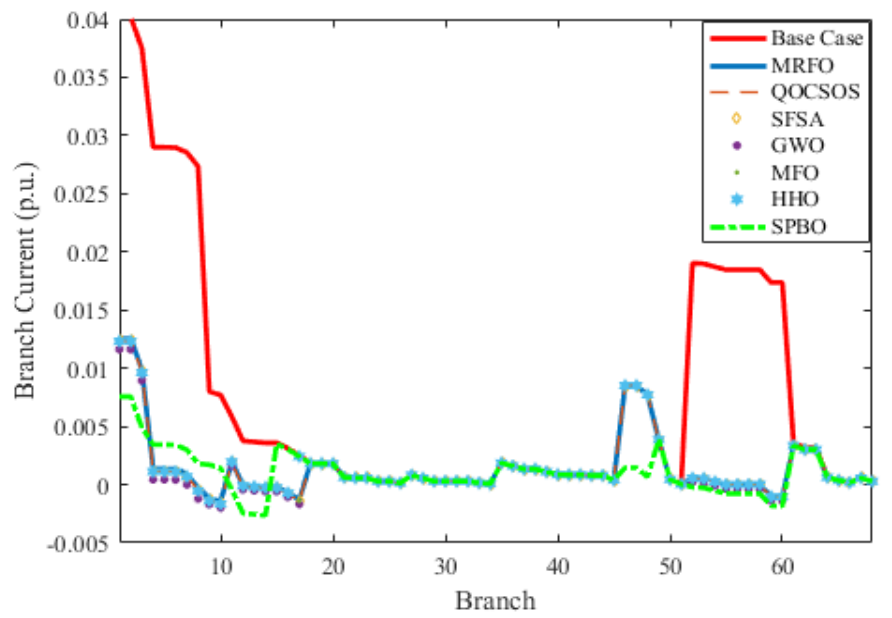

Figure 8. Branch current of 69-node DN with and without DGs 


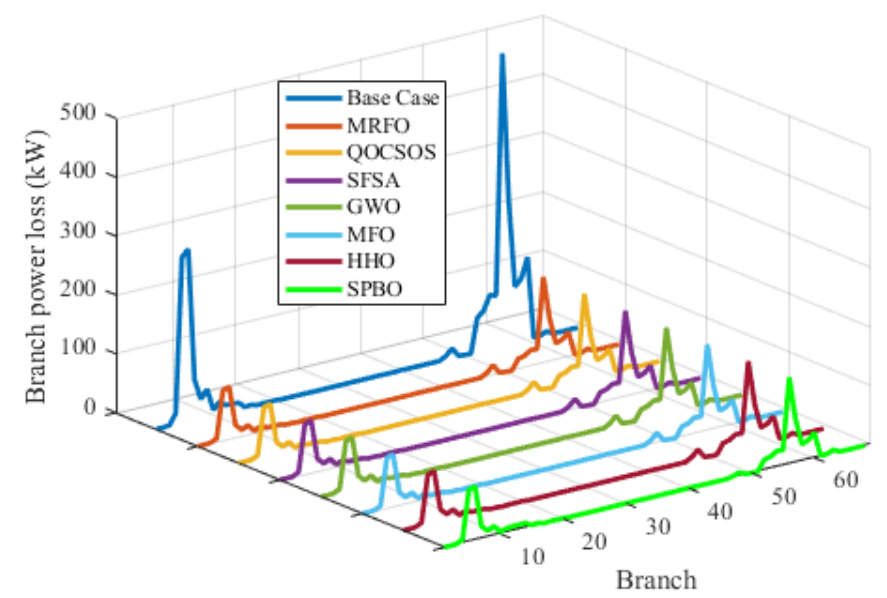

Figure 9. Branch power loss of 69-node DN with and without DGs

In Figure 9, a comparison of branch loss profiles for the base case along with for all compared methods have been presented for the 69-bus system. It is worth noting that in presence of optimally allocated DGs the branch-wise power loss is significantly reduced than the base case system.

\section{84-node DN}

The proposed approach is also tested on a 84-node radial distribution network [7] which has a total real and reactive power demand of $28350 \mathrm{~kW}$ and $20640 \mathrm{kVAr}$ respectively. The said test system has a real and reactive power loss of $530.91 \mathrm{~kW}$ and $1370.7 \mathrm{kVAr}$ respectively prior to the integration of DGs into the network. The system experiences a minimum voltage of 0.9285 p.u. at $10^{\text {th }}$ node.

In Table 4, the optimal allocations (locations and sizes) of DGs for minimizing real power loss of the system using proposed approach is presented. Table 4 also compares the best results obtained by recently reported different optimization techniques to determine the locations and sizes of DGs to optimize the real power loss. Using SPBO algorithm the real power loss of the system has been reduced from $530.91 \mathrm{~kW}$ to $359.6663 \mathrm{~kW}$ which is the lowest among the reported approaches. Locations for DG integration obtained by the proposed method are different than other reported methods except for the first node. Figure 10 shows the convergence characteristic of the proposed SPBO algorithm in optimizing the real power loss of the DN. Voltage profile and branch current of the DN with and without integration of DGs are depicted in Figure 11 and Figure 12 respectively. It is clear that in presence of the DGs the system operates at a much better voltage profile than without DGs. The voltage and current profile obtained for OADG solved by SPBO and SFSA [26] are almost overlapping because of the almost similar capacities of PV DGs as reported in Table 4. A reversal of branch flow can be noticed in branches adjacent to the DGs interconnected nodes. However, the magnitude of this reverse current is negligible as can been from Figure 12. In Figure 13, a comparison of branch loss profiles for the base case along with for all compared methods have been presented for the 84-bus system. It is worth noting that in presence of optimally allocated DGs the branch-wise power loss is significantly reduced than the base case system. 


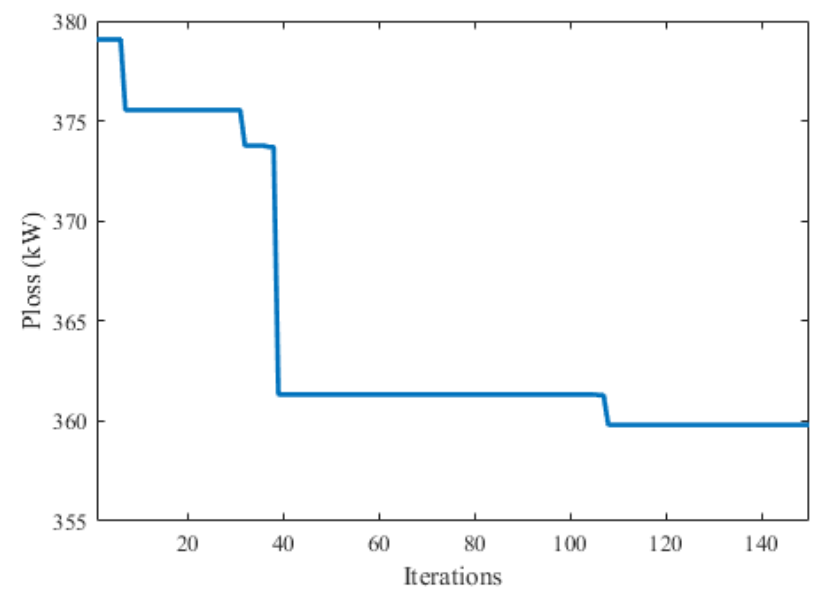

Figure 10. Convergence characteristic of SPBO algorithm for 84-node DN

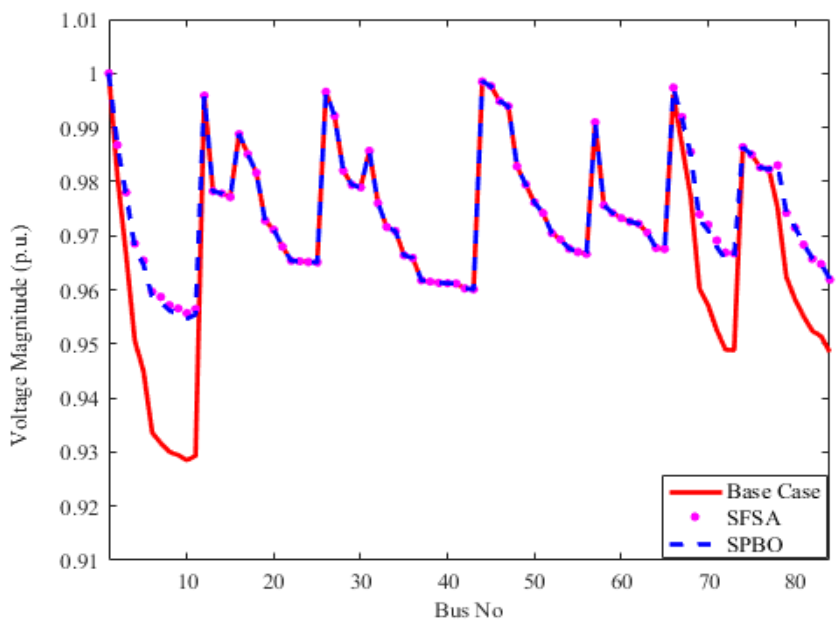

Figure 11. Voltage profile of 84-node DN with and without DGs

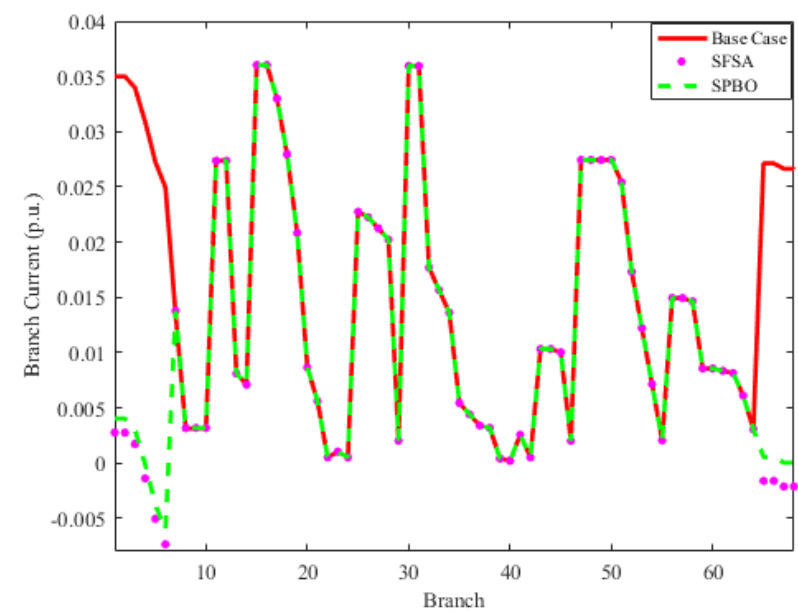

Figure 12. Branch current of 84-node DN with and without DGs 
Table 4. Comparison of results for 84-node DN

\begin{tabular}{|c|c|c|c|}
\hline Methods & $\begin{array}{c}\text { DG } \\
\text { Location }\end{array}$ & $\begin{array}{c}\text { DG Size } \\
\text { (MW) }\end{array}$ & $\begin{array}{l}\text { Ploss } \\
(\mathrm{kW})\end{array}$ \\
\hline \multirow{3}{*}{ SFSA [26] } & 80 & 3.5847 & \multirow{3}{*}{359.7211} \\
\hline & 72 & 2.8350 & \\
\hline & 7 & 3.1389 & \\
\hline \multirow{3}{*}{$\begin{array}{l}\text { SPBO } \\
\text { (Proposed) }\end{array}$} & 7 & 3.0118 & \multirow{3}{*}{359.6663} \\
\hline & 73 & 2.6207 & \\
\hline & 80 & 3.6140 & \\
\hline
\end{tabular}

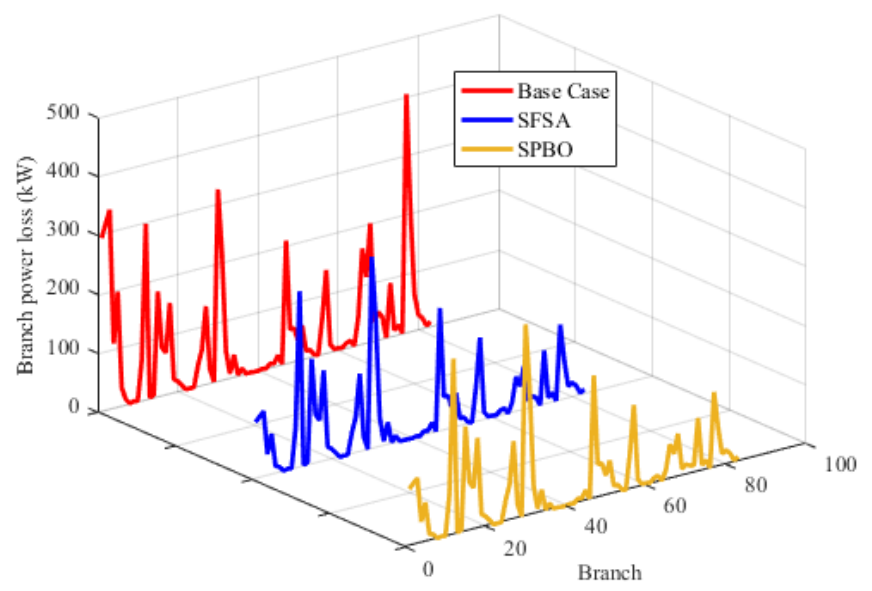

Figure 13. Branch power loss of 84-node DN with and without DGs

\section{Conclusion}

In this paper simultaneous placement and sizing of multiple PV units using a newly proposed student psychology-based optimization algorithm has been carried out for minimizing the real power loss of the system by considering realistic constraints. In order to implement the SPBO algorithm to a first ever engineering problem such as OADG, the proposed student classification scheme based on normally distributed student performance has been successfully incorporated. To prove the superiority of the proposed approach, it has been validated on three standard test systems namely 33-node, 69-node and 84-node radial distribution networks. The results obtained have been compared with the recently proposed metaheuristic approaches (SFSA, MRFO, QOCSOS, GWO, MFO, HHO) for solving OADG problem and it has been found that the proposed method has been able to obtain the better solutions each time. Further, all considered systems have also been found to operate at much better voltage profiles with zero branch flow violations in presence of optimally allocated PV-DGs.

\section{References}

[1]. M. G. Hemeida, Ibrahim, A. A. Mohamed, S. Alkhalaf, and A. M. Bahaa El-Dine, "Optimal allocation of distributed generators DG based Manta Ray Foraging Optimization algorithm,", Ain Shams Engineering Journal, vol.12, pp. 609-619, 2021.

[2]. T. Ackermann, G. Andersson, and L. Soder, "Distributed generation: A Definition", Electric Power System Research, vol.57, pp.195-204, 2001.

[3]. P. Glanville, "Letting in the Light: How Solar Photovoltaic Will Revolutionise the Electricity System", IRENA, vol. 575, June- 2016. 
[4]. K. H. Truong, P. Nallagowndena, I. Elamvazuthia, and D.N. Vo, "A Quasi-OppositionalChaotic Symbiotic Organisms Search algorithm for optimal allocation of DG in radial distribution networks", Applied Soft Computing Journal, vol. 88, pp.1-25 2020.

[5]. B. Das, V. Mukherjee, D. Das, "Student psychology-based optimization algorithm: A new population-based optimization algorithm for solving optimization problems". Advances in Engineering Software, vol.146, pp.1-17, Aug-2020.

[6]. S. Mishra, D. Das, S. Paul, "A Simple Algorithm for Distribution System Load Flow with Distributed Generation", International Conference on Recent Advances and Innovations in Engineering (ICRAIE-2014), pp 1-5, Jaipur, India, 2014.

[7]. S. Mishra, D. Das, S. Paul, "A comprehensive review on power distribution network reconfiguration”, Energy Systems, vol. 8, pp. 227-284, 2017.

[8]. T.P. Nguyen, and D.N. Vo, "A Novel Stochastic Fractal Search Algorithm for Optimal Allocation of Distributed Generators in Radial Distribution Systems", Applied Soft Computing Journal, vol. 70, pp.773-796, 2018.

[9]. S.R. Gampa, and D. Das, "Optimum placement and sizing of DGs considering average hourly variations of load", International Journal of Electrical Power and Energy Systems, vol. 66, pp. 25-40, 2015.

[10]. S. Barik, and D. Das, "Determining the sizes of renewable DGs considering seasonal variation of generation and load and their impact on system load growth", IET Renewable Power Generation, vol. 12, pp.1101-1110, 2018.

[11]. U. Raut, S. Mishra, and D.P. Mishra, "An adaptive NSGA II for Optimal Insertion of Distributed Generators in Radial Distribution Systems", International Conference on Information Technology (ICIT-2019), 2019.

[12]. S. Nematshahi, and H.R. Mashhadi, "Application of Distribution Locational Marginal Price in optimal simultaneous distributed generation placement and sizing in electricity distribution networks", International Transaction Electrical Energy System, vol. 29, May2019.

[13]. C.H. Prassad, K. Subbaramaiah, P. Sujatha, "Cost-benefit analysis for optimal DG placement in distribution systems by using elephant herding optimization algorithm", Renewables: Wind, Water and Solar, vol.6, pp.01-12, 2019.

[14]. S. Kumar, K.K. Mandal, N. Chakraborty, "Optimal DG placement by multi-objective opposition based chaotic differential evolution for techno-economic analysis", Applied Soft Computing Journal, vol. 78, pp.70-83, 2019.

[15]. M. C. V. Suresh and J. B. Edward, "A Hybrid Algorithm Based Optimal Placement of DG Units for Loss Reduction in the Distribution System", Applied Soft Computing Journal, vol. 91, 2020.

[16]. S. Nagaballi, and V.S. Kale, "Pareto optimality and game theory approach for optimal deployment of DG in radial distribution system to improve techno-economic benefits", Applied Soft Computing Journal, vol. 92, pp. 2-13, 2020.

[17]. U. Raut, and S. Mishra, "A new pareto multi objective sine cosine algorithm for performance enhancement of radial distribution network by optimal allocation of distributed generators", Evolutionary Intelligence, 2020.

[18]. A. Khodabakhshian and M. H. Andishgar, "Simultaneous placement and sizing of DGs and shunt capacitors in distribution systems by using IMDE algorithm". International Journal of Electrical Power \& Energy Systems, vol. 82, pp.599-607, 2016.

[19]. S.R. Gampa and D. Das, "Simultaneous optimal allocation and sizing of distributed generations and shunt capacitors in distribution networks using fuzzy GA methodology", Journal of Electrical Systems and Information Technology, vol. 6, pp. 1-18, 2019.

[20]. K. Mahmoud and M. Lehtonen, "Simultaneous Allocation of Multi-Type Distributed Generations and Capacitors Using Generic Analytical Expressions", IEEE Access, vol. 7, pp.182701 - 182710, 2019. 
[21]. S.R. Gampa, S. Makkena, P. Goli, and D. Das, "FPA Pareto optimality-based multi objective approach for capacitor placement and reconductoring of urban distribution systems with solar DG units", International Journal of Ambient Energy, 2020.

[22]. E.A. Almabsout, R.A. El-Sehiemy, O. N. U. An, Bayat O., "A hybrid local SearchGenetic algorithm for simultaneous placement of DG units and shunt capacitors in radial distribution systems", IEEE Access, vol. 8, pp.54465-54481, 2020.

[23]. H. Teimourzadeh, and B.M. Ivatloo, "A three-dimensional group search optimization approach for simultaneous planning of distributed generation units and distribution network", Applied Soft Computing Journal, vol. 88, 2020.

[24]. U. Raut, and S. Mishra, "An Improved Sine Cosine algorithm for simultaneous network reconfiguration and DG allocation in power distribution systems", Applied Soft Computing Journal, vol. 92, pp.1-25, 2020.

[25]. H.B. Tolabi, A.L. Ara, and R. Hosseini, "A new thief and police algorithm and its application in simultaneous reconfiguration with optimal allocation of capacitor and distributed generation units", Energy, vol. 203, 2020.

[26]. T.T Tran, K.H. Truong, D.N. Vo, "Stochastic fractal search algorithm for reconfiguration of distribution networks with distributed generations", Ain Shams Engineering Journal, vol. 11, pp.389-407, 2020.

[27]. S.R. Ghatak, S. Sannigrahi, P. Acharjee, "Comparative Performance Analysis of DG and DSTATCOM Using Improved PSO Based on Success Rate for Deregulated Environment”, IEEE Systems Journal, vol. 12, pp.2791-2802, 2017.

[28]. F. Iqbal, M.T. Khan, and A.S. Siddiqui, "Optimal placement of DG and DSTATCOM for loss reduction and voltage profile improvement”, Alexandria Engineering Journal, vol. 57, pp.755-765, 2018.

[29]. S. Ganesh, R. Kanimozhi, "Meta-heuristic technique for network reconfiguration in distribution system with photovoltaic and D-STATCOM", IET Generation, Transmission \& Distribution, vol. 12, pp.4524-4535, 2018.

[30]. S.R. Gampa, K. Jasthi, P. Goli, D. Das, and R.C. Bansal, "Grasshopper optimization algorithm based two stage fuzzy multi-objective approach for optimum sizing and placement of distributed generations, shunt capacitors and electric vehicle charging station", Journal of Energy Storage, vol. 27, pp.1-23, 2020.

[31]. B. Mukhopadhyay, and D. Das, "Multi-objective dynamic and static reconfiguration with optimized allocation of PV-DG and battery energy storage system", Renewable and Sustainable Energy Reviews, vol. 124, 2020.

[32]. A. Pal, A. K. Chakraborty, and A. R. Bhowmik, "Optimal Placement and Sizing of DG Considering Power and Energy Loss Minimization in Distribution System", International Journal on Electrical Engineering and Informatics, vol. 12, no. 3, pp. 624-653, September 2020.

[33]. P. V. K. Babu, and K. Swarnasri, "Optimal Integration of different types of DGs in Radial Distribution System by using Harris Hawk Optimization Algorithm", Cogent Engineering, vol. 7, no. 1, pp. 1-36, Oct. 2020.

[34]. P. Khetrapal, J. Pathan, and S. Shrivastava, "Power Loss Minimization in Radial Distribution Systems with Simultaneous Placement and Sizing of Different Types of Distribution Generation Units Using Improved Artificial Bee Colony Algorithm", International Journal on Electrical Engineering and Informatics, vol. 12, no. 3, pp. 687707, September 2020.

[35]. U. Raut, and S. Mishra, "Enhanced Sine Cosine algorithm for optimal planning of distribution network by incorporating network reconfiguration and distributed generation", Arabian Journal of Science and Engineering, vol. 46, pp.1029-1051, 2021.

[36]. IEEE P1547 Standard for Distributed Resources Interconnected with Electric Power Systems, IEEE P1547 Std., Sept. 2002. 


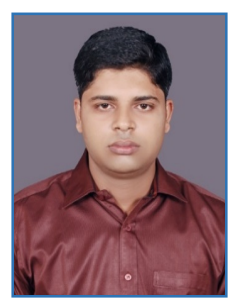

Subrat Kumar Dash is presently working as an Assistant Professor in Department of Electrical Engineering, Government College of Engineering, Kalahandi, India. He graduated in Electrical and Electronics Engineering from Biju Patnayak University of Technology, Odisha, Rourkela in 2007, received the $M$. Tech degree in Electrical Engineering from Indian Institute of Technology, Kharagpur in 2013 and pursuing PhD (Engineering) at Biju Patnayak University of Technology, Odisha, Rourkela. His research interests include Electrical Distribution System Planning, Soft Computing Applications in Power System and D-FACTS devices. He is a Member of IEEE.

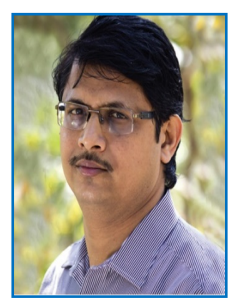

Sivkumar Mishra received the B. E degree from Malaviya Reginal Engineering College, Jaipur (presently known as Malaviya National Institute of Technology, Jaipur) in 1995, M. Tech (Power System Engineering) from Indian Institute of Technology, Kharagpur and $\mathrm{PhD}$ (Engineering) from Jadavpur University, Kolkata. He is currently working as an Associate Professor in Centre for Advance Post Graduate Studies, Biju Patnayak University of Technology, Odisha, Rourkela. His research interests include Intelligent Methods for Power System Planning and Smart Grid related Studies. He is a Senior Member of IEEE and IEEE Power and Energy Society. 